\title{
The Representation of Women in USA Sports, Sports Administrative, and Team Sports Leadership
}

\author{
Ezzeldin R Aly, PhD \\ Associate Professor of Sport Managment \\ Department of Health, Physical Education and Recreation, College of \\ Education, Florida A\&M University, USA \\ Kathryn Breese, M.S, Sport Management
}

Doi: 10.19044/esj.2018.v14n5p55 URL:http://dx.doi.org/10.19044/esj.2018.v14n5p55

\begin{abstract}
Woods (2016, p. 311) stated "For centuries, sports participated in assigning a limited role to women by excluding them from participation and resisting efforts to include them." Women have had to struggle when it comes to sport leadership positions. Women are not usually found in higher level jobs in sport, but they tend to have positions in lower management or lower profile positions. This study is a compilation of research into how people within collegiate athletics in the United States feel about women's employment status in the field. A pilot interview was created and administered to three women: an athletic director, an athlete, and a professor at Florida A \& M University. A survey was created and administered to 30 subjects that have careers in sport leadership positions. The questions were divided into five categories consisting of representation, coaching, equal pay, and team sports. The survey showed that there are mixed feelings in the profession. Two-thirds of the subjects thought that there was a lack of female leadership within team sports. A little over half of the subjects thought that men were more successful in the areas of leadership, coaching, equal pay, representation, and team sports. By identifying the issues that women are facing when heading into this profession, the researchers identified what actions need to take place in order to resolve the problems discovered. In turn, this would create more opportunities and more qualified female candidates for positions in sports administration and team sports leadership in the United States.
\end{abstract}

Keywords: Leadership, sports organization, team sports and sports management 


\section{Introduction}

Clare Boothe Luce said, "A woman must make unusual efforts to succeed. If she fails, no one will say, "She doesn't have what it takes." They will say, "Women don't have what it takes" (Brooks, 1990, p. 143). Luce's words are an example of the way women were viewed in the mid-1900's, and the issue still persists today. There are a wide variety of views about women in leadership positions within the collegiate athletics in the United States. The purpose of this study is to look into what men and women think about women in team sports leadership positions, and why they feel that way. This study allowed the researchers to ask men and women already in the field of team sports leadership if there was still a problem, and if so, how they feel about it, and what needs to be done for women to increase their leadership opportunities. Research that has been carried out on this subject has tended to focus just on the number of women in these sport leadership positions, rather than the reasons behind why there is or is not an underrepresentation of them. A study like this was needed to gain an understanding from men and women who already hold these positions, on the differences in opportunities for men and women in sports leadership, and what changes needed to happen to increase the number of female representatives. This research was needed to gain insight from both sides of the spectrum on a subject that is of critical importance in this era. The researchers believe that sexism and lack of opportunity play a critical role in this underrepresentation.

The increasing equality of the sexes is a very significant accomplishment in recent history. People have more opportunities than ever before to become exactly what they want to be, regardless of their gender. It has only been a few decades that women have really started to break the glass ceilings that were problematic for so many years. As women have begun to prove that they can survive in what was once a "man's" world, more and more women now seek the same positions and opportunities that men have traditionally enjoyed. The unfortunate thing is that it seems that habits and status quo are hard to break. Women have had to fight for so many things that men never had to fight for, such as the right to vote, the ownership of property, the opportunity to receive an education, and to serve in the armed forces. Sports is another arena in which women have not been readily accepted. Even though women participate in the same sports as men, they are still seen as different. They are still seen by some people as a weaker sex, in terms of physical strength, mental strength, social status, and their ability to work in a fast-paced business savvy world.

Additionally, within sports and sports administration in college and above there is a culture of chauvinism. There are still instances of women being objectified and belittled because those within these cultures are ignorant and not forced to adhere to a much higher standard of ethics, morals and 
values. The nature of the "good old boy" network also needs to be understood. Many times coaches, directors and leadership are hired because they rub elbows with the people hiring. Hiring is often already a done deal before the required interview and applicant pool is even complete. Within these systems, it can be difficult for women to have a chance of being hired because many of these men have a superiority complex. Also, many of these people do not think that a woman can do the job, and believe that the players and coaches within the organization would never trust or listen to a female in a position of authority over them.

Women have difficulty breaking into this field because the traditional roles for women for so long was to stay at home, or only work in employment that is traditionally female in nature. Common examples of sexism include: only supporting men's sporting events, male players, or male teams, or the belief that men's teams are "better" than women's teams. A revealed in the interviews carried out for this study, there are athletes, administrators, sportscasters, and other sports personnel who don't associate sexism with the reason women are underrepresented in sports. It is unclear if the women who hold these positions feel as though there is sexism within the industry, but this study will examine the problems women face, and how to best resolve these issues.

\section{Review of Literature}

This review looks into five aspects of sports leadership: coaching, equal pay, representation, and team sports leadership. Many years ago there were women who were in charge of athletic departments, but it was because there was a separation of men and women's athletics. Women were in charge of women's sports and men were in charge of the men's sports teams. In Bill Littlefield's (2015) article, he says after Title IX, these two departments were combined, resulting in women losing their jobs to men. The process of hiring women in sport leadership positions is constantly evolving, and the most important part of the whole process is where/how far the program is taken after being hired. Female athletes made up nearly half of the New Zealand team for the London Olympics; however the same is not said for the coaches or others in management roles. During her research, Sarah Leberman (2012) found that women feel the industry is still a "good old boys' club." One thing she found was that women need to work on building relationships and negotiation skills if they want to be on equal par with men. She also found that out of the 90 national sports organizations, there were only ten female executives. It has proven to be difficult for women to reach top positions.

To be in the field of sports management is a difficult and timeconsuming profession. It is hard to have a family if you are constantly working, which includes weekend and night work. Positive changes are 
beginning to happen within the industry, but it is going to take time for women to reach equality in pay and representation in sports organizations. According to Simmons (2011), throughout history women have been given fewer legal rights and opportunities than men. A woman's key job has been to marry and raise a family, and they have been stereotyped as the weaker sex. Women are knocking over barriers in a variety of professions, including the sports industry; however, while women can enter these fields, it seems as though that is where it stops. They are having trouble breaking down the wall that has prevented them from taking management positions. Whether it is because of stereotyping, power, leadership styles, or the unequal relationships between men and women, there is still a lack of female management candidates.

Some women sports industry today are setting, breaking, and resetting the bar for women. In the article by Winslow (2009), Title IX is one of the greatest achievements of the Educational Amendments of 1972. The law stated that no program that receives Federal funding would be able to discriminate on the basis of sex (Title IX of the Education Amendments of 1972, 20 USC 1681-1688 (1990)). Forty years ago, women learned dances, or learned how to cook, instead of learning about the sport. They were trained to become teachers or nurses, not principals and doctors. Winslow (2009) also says women were told that playing sports was a sign of lesbianism, and by participating they would be portrayed as unattractive. Men were viewed as being able to handle the aspect of teamwork better than women. Women had to raise their own money, make their own uniforms, and after all of that, play in an empty stadium/arena because nobody came to watch them. Marge Snyder, an employee of the Women's Sports Foundation (2015), remembers that women were allowed to compete as long as they didn't make any effort to publicize their accomplishments. C. Vivian Stringer, now the head coach for Rutgers Women's Basketball team, used to coach at the HBC Cheney State in 1971. She had to spend her own money on the recruitment process, driving players to games in an old jail bus. However, the emerging equal rights movement affected the world, and the sports industry in particular. Winslow (2009) said Patsy Mink and Edith Green introduced Title IX in 1972, but the bill received very little attention until the "Battle of the Sexes" tennis match between Billie Jean King and Bobbie Riggs, in which King defeated Riggs. After that match, women began to change the way they looked at themselves. All of these things combined led to increased interest, participation, and funding for women's sports. Within one year of the passing of Title IX, girls were able to receive scholarships, had money for uniforms and equipment, and no longer had to pay their travel expenses to get to their games.

Though there is much work yet to do, Title IX has benefitted women immensely and given them opportunities at the amateur and professional level that they didn't have before. There are many success stories of women in sport 
leadership roles. Along with Dr. Jen Welter, Becky Hammond with the Spurs, and Marge Snyder, there is Ms. Julie Hermann at Rutgers. According to Kies (2014) the number of girls participating in sports (1972-present) has grown from 300,000 to over 3 million. There were more female Olympic athletes than men during the last Olympics, and more female collegiate athletes than ever. Kies (2014) also states that the number of current women in leadership roles of men's sports is between $2 \%-3.5 \%$.

Kies (2014) studied how women in sport management positions are able to promote social change. She states that anyone in a position of power can increase social change if they are willing to put in the work. Her study shows that when a woman is an athletic director, the number of women coaches within that organization is higher, and when the athletic director is a male that the number of female coaches seems to be lower. This season, the Arizona Cardinals hired the first female coach in the league's history, but her position only lasted until the end of preseason. Dr. Jen Welter has been playing football for over 15 years. She was a linebacker for the Dallas Diamonds of Women's Football Alliance, and then became the running back for Texas Revolution of Champions Indoor Football, which is a men's league. The players she now coaches say she is helping them with their technique, which she is a stickler for. They also say it's easy to forget she's a woman when she's giving technical input.

One major criticism of women coaching men's teams is whether or not someone can coach a sport they have never played before. The NFL is a lot different than the indoor and women's leagues that Dr. Walter has been a part of. ESPN's Mike Rodak (2016) says Kathryn Smith has been hired as the first full-time female coach for the Buffalo Bills. She began her career as a game day/operations intern and worked her way up into her position as coach. According to the Women's Sports Foundation (2015) unequal funding is a critical aspect of why women have less incentive to push themselves in their sport, ultimately steering themselves away participation. Women comprise more than half of the student population in college, yet they receive less than half of the participation opportunities in sport. Although there has been an increase in favor of women, male athletes still receive $55 \%$ of all athletic scholarship dollars. Even the coaches for men's teams make more money than the coaches for female teams. "Men's coaches are pulling in $\$ 3,430,000$ while women's coaches are only making \$1,172,400" (Women's Sports Foundation 2015).

In the article "The Role of Sport in Addressing Gender Issues" (International Platform on Sport and Development 2013), women and girls' health and well-being is positively affected by physical activity. Also, women's self-esteem and self-empowerment are increased, as well as feelings of accomplishment. Women and girls who participate in sports have a better 
perception of their physical appearance and personal freedom. Sports give women and girls the safe space they need to exercise control and ownership of themselves and the sport they love to be a part of. Sports encourages social interaction between women. According to the article "Women, Gender Equality and Sport" (UN 2007), the participation of women in sport has a problematic history. Discrimination has been a major issue, but there have also been significant advancements as well. They have occupied leadership positions like coaching, management, officiating, and broadcasters or journalists. Women have been viewed as being too weak for sports, especially ones that involve a lot of endurance. Efforts to increase women in leadership positions show that those there has been an increase it is mostly due to quotas or laws that have been put in place to place women in these positions. Men's sports still dominate media coverage, and receive the majority global attention.

Despite the increase in the number of women participating in sports, there is a lack of women in leadership positions in the industry they have dedicated their lives to. When we consider the underrepresentation of women within this field, we have to gain an understanding from those women already in the program. Understanding why they are in the field is important. These understandings could also help attract more female students to the program. Aicher, Grappendorf, Harris, and Veraldo (2014) state the chilly climate of the classroom is also relevant. When women are in a male-dominated classroom, they tend to be treated differently. This could be by discouraging female participation or sexist jokes. Professors can also treat women differently by making more eye contact with men, giving better instruction to men, or calling on them more in classroom discussion. This may discourage women from entering the field. Another obstacle for women is their peers or parents' views on their choice of an undergraduate major.

Media largely shape the public's view of the achievements of women within the sports industry. It also shapes the visions and ambitions of girls. According to Lopiano (2008), television is a crucial part of the success of a professional women's team. If women cannot maneuver their way into the big advertisement deals, their salaries will continue to dwindle and the financial success of women professional sports will not succeed. Media coverage of women's sports at this time is inconsistent and in some cases non-existent. The ratings were successful for the female athletes in the Olympics and World Cup, but those are events that only happen every few years. While these events receive the ratings, publicity, and acknowledgment, the rest of the seasons are almost invisible to the public unless they attend the games physically. Men often receive attention on their skills or performance, whereas women gain attention because of their looks or non-sport-related activities. This diminishes the athleticism of these women compared to their male counterparts. When evaluating finances in sport, women are receiving far less in terms of 
endorsements and sponsorship in comparison to men. In Smith's (2015) article, the Repucon study shows that men's and women's interest in the sport has changed in the last 50 years. Nearly fifty percent of all women categorize themselves as either interested or very interested in some aspect of the sport. In the past women have tended to gear their interest towards music, travel, movies, arts, culture, and social interests. Men tended to focus more on technologies and athletics.

\section{Methodology}

There were a total of 30 subjects interviewed throughout this research. There were fifteen men and fifteen women, who were collegiate athletes, sports journalists, sport management professors, sports administrators, athletic directors and team sport head coaches. The subjects were randomly selected by the researchers. There were five high school athletic directors, ten collegiate athletes (four soccer players, three football players, and three baseball players), three ESPN sportscasters, seven collegiate athletic administrators, and eight were a part of the academic side of athletics who taught sport management classes. The subject pool consisted of fourteen African Americans, ten Caucasians, and six Latin Americans. Each race was divided into equal parts: male and female. The age range for the subjects ranged from 22 years old to 50 years old. Interviews are a form of qualitative research, and was deemed the best way for the researchers to gather information on the topic. There was much brainstorming associated with building the interview for this research. After three meetings, the researchers were able to divide the topic being examined into five parts: leadership, coaching, equal pay, presentation, and team sports. Each section was different, but each of the three questions for each category enabled the researchers to dive deeper into the problems at hand. Three pilot studies took place to ensure the validity of the questionnaire, and were then edited by the researchers to better suit the study (see Appendix I). The researchers created questions for the interview. The questions were randomly selected by the researchers to gather information on people's views about women in sports leadership roles (see Appendix II). The questions were then modified to make the interview more suitable for the research. The questions were written so that a specific "either-or" response was received for numerical data, but each one left room for the subject to respond with more than a simple "yes" or "no" response. Each interview was done face-to-face with the exception of three, due to their location. Two of those interviews were done over the phone, and one was done through email. The interviews were recorded on a tape recorder. There were also notes taken with pencil and paper by the researcher while the questions were being asked. The subjects were made aware that all responses were for research purposes only, and their identity would not be used in the study. 30 
minutes was allotted for the interview time, and all (with the exception of two) were completed within twenty minutes. The researchers used the SPSS program to analyze the data and reach the outcomes. SPSS is a software package used for statistical analysis. It includes descriptive statistics, bivariate statistics, and the frequency and average for statistics. The researchers coded the results, changing the verbal data into numerical data. The program allowed for the researchers to create graphs and organize data to add validity for the following results.

\section{Results}

All subjects were asked if women are sufficiently represented in sports leadership, $30 \%$ said yes, and $70 \%$ said no. The subjects were then asked if they think there is need to have an increase in female involvement within these positions $83 \%$ said yes with $17 \%$ said no. The final representation question was if the subjects thought women were represented positively within this roles $73 \%$ said yes, while $27 \%$ said no. Coaching was discussed next $67 \%$ of the subjects stated that men are more successful coaches, with $33 \%$ said no. When asked if women can coach all-male teams, $57 \%$ said yes, while $43 \%$ said no. The subjects were then asked if teams with female coaches are looked at as weaker than those coached by men, $23 \%$ said yes with $77 \%$ said no. When discussing the issue of equal pay, $7 \%$ of the subjects stated that women are paid as much as men in regards to professional salary with $93 \%$ disagreed. The subjects were then asked if they thought women received more in collegiate scholarship than men $99 \%$ said no. In regards to scholarship money, $70 \%$ of the subjects felt as though women were deserving of the same amount of money as male athletes, $30 \%$ thought men should receive more money. When asking about representation in sports leadership positions, the results were split down the middle with $50 \%$ women said women have the same opportunities as men, and $50 \%$ said they do not. $40 \%$ of the subjects feel as though there are enough women working as athletic directors, while $60 \%$ feels there needs to be an increase. When asked if these positions in team sports leadership are geared more towards men than women, $87 \%$ said yes, with $13 \%$ said no. $3 \%$ of the subjects thought that women are represented in the media to the extent of men, and $97 \%$ felt they are not. When asked if Title XI is doing what it's supposed to do for women, $40 \%$ said it was, while $60 \%$ said it was not. The final question was whether or not an all-male team would happily welcome a female onto their team and $47 \%$ said a female would be welcomed, but $53 \%$ felt they would not. (Leadership). $62 \%$ agreed that there is a lack of women in team sports leadership \& (Coaching). 51\% agreed that men are the dominant and more successful coaches \& (Equal Pay). 74\% disagreed that women are paid more in regards to salary and scholarship \& (Team Sports). $59 \%$ disagree that women have the same opportunities as men in team sports 
leadership \& (Representation). 63\% disagreed that female teams are represented to the extent of male teams.

\section{Discussion}

Sports are a very prominent social institution in almost every society. Eitzen et al. (1991) suggested that the "Sport is an arena of patterned behaviors, social structures, and inter-institutional relationships that holds unique opportunities to study and understand the complexities of social life" (P 503 -522). Sport is an activity that commands a degree of primary or secondary involvement unsurpassed by other institutionalized settings. Sport offers an opportunity for research on "highly crystallized forms of social structure not found in other systems or situations" (Luschen 1990:59). This current study presupposes that the structure or forms of behavior and interaction found in sports settings are similar to those found in other societal settings. In other words, sport, like other institutions, is a microcosm of society. At the same time that sport is a product of social reality - women are less represented in the sports job market compared to their representation in the social structure of the sport. Sexism and lack of opportunity have played a critical role in this underrepresentation, according to the results of the research interview. After the interviews we conducted, it was clear how much sexism still exists in today's world, and it's not only the men being sexist towards the women. Some women showed signs of sexism amongst themselves. The idea that women couldn't lead the way men could, and that they are the lesser of the two sexes was still so much a part of the discussion during these interviews. It was clear throughout the interview that women are not represented to the same degree as men in regards to team sports leadership. There are more men that hold these positions than women. Women do not get the same opportunities as men. More people throughout the study felt that men were more successful in regards to coaching than women. Also found, was the idea that male teams are presented in the media on a grander scale than female teams. Other than the Olympics and the women's World Cup, people hardly see female sports on television. There is almost always some male sporting event on television, or even a rerun of an old male sporting event. Men's football teams are bringing in more revenue than women's teams, so universities and professional programs are going to spend more on them, which brings up the idea of equal pay. Men are receiving more money in scholarship and professional salary than women. As seen from the interviews, some of the same people in these positions do not think that a woman can do the job, and that the players and coaches within the organization would never trust or listen to a female. Women struggle to cross these lines because they aren't given the opportunity to do so. Some sports sociologists have embraced a cultural studies approach sport-related phenomena. From this perspective, 
both functional and conflict views are challenged because they are deterministic, that is, they tend to ignore or terminate human agency in social change. Also, both theoretical perspectives are considered faulty because they omit the significance of cultures imperatives, where sport is seen as a cultural appearance. In this current study, sport is a publically assembled arena where developmental and evolving features are of key significance. Canadian and European scholars have taken the lead in writing from this perspective (Gruneau 1983, Hargreaves 1986), followed by American scholars (MacAloon 1987, Harris 1989, Birrell 1989). History has shown that women involved in sports have for the most part been involved in the jobs behind the scenes. There is a difference between the reality of what's going on within these positions and what is said to be going on. Big universities are doing the bare minimum to stay with NCAA and Title XI regulations. $62 \%$ of the subjects agreed that there is a lack of women in team sports leadership. The majority of the subjects think there needs to be an increase in female involvement within athletic administration, but that the women who hold these positions are presented in a positive way. The subjects who disagreed that women are represented sufficiently said women tend to have the jobs below the leadership positions. They hold jobs like secretaries, marketing associates, or basic sales positions. The people who agreed said that Title IX was ensuring we have those positions filled. When the subjects were asked about whether or not there needs to be an increase of women in these positions, the $83 \%$ agreed that women should have the same rights as men and have the same leadership skills to do that job. On the other hand, the ones who disagreed thought that women could not do the same job as their male counterparts, and that women were far too emotional to handle the high stress jobs. The subjects were asked if women were presented in a positive manner within sport leadership, $73 \%$ of the subjects answered yes, and had the reason that women are perfectly capable of getting these jobs done, and done well. The ones who disagreed stated that women are not given the opportunity to gain a positive representation, and that they cannot be positively presented in a maledominated society. 51\% agreed that men are the dominant and more successful coaches. $66.7 \%$ of the subjects agreed that men make better coaches due to the fact that men are more aggressive and respected in a leadership role. The subjects also thought that teams with female coaches are looked at as weaker than those coached by men, but women were capable of those coaching positions. When the subjects were asked if men are more successful coaches than women, $66.7 \%$ of the subjects agreed that men have the respect, aggressiveness, and societal backing that women do not have. Society views men as being more dominant in a leadership setting. The subjects who disagreed thought that coaching had little to do with the sex of the coach, but everything to do with ability. The subjects were asked about if women can 
coach all-male teams, 56.7\% said women could, and the only argument for women was that they can successfully do anything a male can do. The subjects who disagreed thought that men didn't feel like women could coach a sport they have never played. The subjects also thought that men felt that they couldn't relate to a female coach. There were also subjects who thought female players couldn't relate to a male coach. When it came to the way teams are viewed with a female coach rather than a male coach, $73.3 \%$ of the subjects felt that women were viewed as the weaker sex. This means they thought that the teams would be viewed as weaker as well. The subjects also thought that women didn't know the basics of male sports. $74 \%$ disagreed that women are paid more in regards to salary and scholarship. The subjects agreed that men receive more money in scholarship and salary, but disagreed that they should be paid the same because women didn't bring in enough revenue to get paid as much. When asked if women receive more money in collegiate scholarship, $99 \%$ of the subjects who disagreed said that women don't play big business sports like football. Women aren't bringing in the money that male sports are bringing in, so why would they receive more in scholarship? This brought the question of whether the subjects thought women should receive as much scholarship money as men. The subjects thought that Title IX should be making sure that that happens, and that because collegiate sport is amateur they should be treated equally. Title IX or Affirmative Action Legislation (1972) was designed to eliminate discrimination against women, especially in access to facilities, equipment, financial aid, and opportunities to participate in any sport. Title IX couldn't solve all problems connected with discrimination because was only applied to the programs receiving federal funds (Sabo 1988). Before title XI, 90\% of women's team were coached by women; in 1989, 47\% were coached by women. Correspondingly, the administrators of women's sports job opportunity tend be men, and most female sport administrators are managed by men. Feminist social theorists state that sport is one of many social systems that is male-controlled (Birrell 1984, Hall 1988). The initial argument of feminist social theory is that authority arrangements are dominated by men, because social structures are male-controlled (Hall 1988). The researchers believe that the sociology of sports will be able to shed more light on all of these issues when theory informs more of the research in this subfield. The subjects who disagreed again went back to the idea of big business and the women just not bringing in the same amount of money. 59\% disagreed that women have the same opportunities as men in team sport leadership. There was an equal split on whether the opportunities for men and women were even. $60 \%$ of the subjects thought there were not enough women working as athletic directors, and thought that due to the fact that most positions within sport leadership were geared more towards men than women. The subjects were then asked whether women get 
the same opportunities as men within sport leadership, men were the only sex who agreed that the amount of opportunities for women was sufficient. Men said that women didn't want those positions, not that men didn't want them to have them. The subjects who disagreed stated men are preferred coaches, they are stronger in business, and that there are sports that only men can play. When asked if there were enough women working as athletic directors, it was stated that women take A.D. jobs in high schools more than universities due to the time consumption of the job and the idea that women want to have families and lives. $50 \%$ of the subjects agreed that there are enough opportunities out there, but women just don't want them. The subjects were then asked if positions within sport leadership are geared more towards men than women. Again, there were subjects who stated that everyone has the same opportunities. $86.7 \%$ of the subjects agreed that the positions were geared toward men thought that men bring in the money more so than women, so more male players, coaches, and businessmen are desired. It was stated by female subjects that sexism played a huge role in this scenario. $63 \%$ disagreed that female teams are represented to the extent of male teams. The subjects did not feel that female teams are presented in the media coverage to the extent of male teams. The subjects don't feel like Title IX is really doing what it is supposed to do. When it comes to male teams, $53.3 \%$ of the subjects thought that women would not be welcomed to an all-male team because they could not keep up with their male counterparts. The subjects were asked if female teams are represented in the media to the extent of male teams. $3 \%$ of the subjects felt that both female and male sports are aired, especially collegiate sports. The subjects who disagreed said people would rather watch male sports because they are more exciting and entertaining. Coakley (1990) explained that the existence of sport must be explained in terms of something more than simply the needs of the social system or the production needs of a capitalist economy. Sports is created by people interacting, using their skills and interests to make sports into something that meets their interests and needs. Melanie et al. (2012) suggested that the "females are vastly under-represented in the upper echelons of sport organizations" (P.224) contributing to an overall lacking presence of women in leadership positions of sport organizations" The subjects also stated that there weren't enough female professional leagues to be equal to male leagues. The next question asked to the subjects was in regards to whether or not Title IX was really doing what it was created to do. $40 \%$ of the subjects stated yes because if it wasn't, the schools would be getting fined and penalized for not fulfilling their responsibility. The subjects who said no stated that administrators are just filling those positions to meet the quota. The final question was whether the subjects felt that men would happily welcome a female to their male-dominated team. $83 \%$ of the subjects said no stated that sexism played a role. They also said they would be fearful 
of injuries the women would endure participating with men, and that there would be a heightened risk of sexual misconduct scenarios taking place. The subjects stated that men would welcome a female stated that the men would welcome diversity, and that there might actually be benefits to the team with the female player participating.

\section{Conclusion}

The researchers proved their hypothesis with the fact that there is less representation of women in team sports leadership. Changes in sports society by having more opportunity for women to have equal sports leadership opportunities are also important to cultural studies theorists. Sport is "produced" out of everyday life (Gruneau 1983). Thus, people act to create their institutions; they are not simply passive responders. At times, however, the design of sport is not always desirable (e.g. female athlete cannot easily find job opportunities in sports). This current study suggests that people still feel as though women cannot hold these sports leadership positions, and that men are the more suitable for the job. It was clear most of the women thought they could handle the job, and felt that men weren't giving them the opportunities they needed to excel in this field. Most of the men felt that women didn't want these jobs, and that the lack of women within these positions was due to the women not wanting them or that they didn't understand the games. This study shows how much sexism is still a part of today's world. The men, and even a few women, who answered these questions in a sexist way didn't even realize their views were sexist in the first place. It showed that changes need to be made to give women more opportunities and more of the tools they need to prosper in this field. It also shows that much has changed since the passing of Title IX, but that there is still much to do. Sport offers an opportunity for research on "highly crystallized forms of the social structure; not found in other systems or situations" (Luschen 1990:59).

\section{Limitations}

There were few limitations that took place while conducting this research. It would have been beneficial look at other areas of discrimination like homophobia, racism, and cultural backgrounds. There is so much information that would come along with those topics and there was not enough time or resources to accomplish those studies. Another limitation was the number of subjects interviewed. Only 30 interviews took place. Studies have shown that the more subjects made readily available, the more data that can be collected. This would have created a larger subject pool, and more information could have led to stronger results. To conclude, there is a limitation of how the interview was administered. Almost all of the interviews 
were administered by face-to-face, however, three of those interviews were done via phone calls and emails. The researcher might have found the subjects body language or responses were different if they were sitting in front of the subjects asking the questions. Skype may have been a better way of conducting those interviews so that the researcher could see the subjects as they answered questions.

\section{Recommendation}

In the last 50 decades after Title XI, the time has shown changes that many people felt were not possible, but there is still a gap. How does society make a change for the better? How is the lack of women represented in team sports leadership changed to create a more equal opportunity for both men and women? First, it is important to create more opportunities for those women. There is still a large number of people who feel that women cannot do the same job as well as their male counterparts. An issue that may never be fully be reversed, sexism is something that can be discussed with both men and women. Bringing more awareness to the concept of sexism, and how much it still exists in the world could be beneficial. The more that the topic is discussed, the more it can be identified which will enable changes to be made. Having more successful women's professional teams will be helpful as well. Changes in social media and promotion for women and these positions will encourage more young girls to strive for their goals. Instead of promoting women athletes and teams when they are champions, start promoting them during the offseason as well. The younger generations need to see the proof that women can achieve and excel in these positions. Creating more workshops and conferences on female leadership within the sports realm could increase female involvement. This would be helpful and aid in the recruitment of women into sports management or leadership majors. The more women that are getting their education in these fields, the more opportunities there will be for them to be a part of this profession. The biggest aspect associated with shifting societies' views on women within team sports leadership is time.

\section{Appendix I \\ Pilot Study}

Leadership: Do you think that women are adequately represented in sports leadership?

Do you think there needs to be an increase in female leadership?

Are women presented positively or negatively within sports leadership?

Coaching: Do you think men or women are more successful coaches?

Do you think women can coach all-male teams? Vice versa?

Do you think that teams with female coaches are viewed as weaker than those coached by men? 
Equal Pay: Do you think that women or men are paid more in regards to professional pay?

Do you think that women or men receive more money in collegiate scholarship? Why?

Do you think women should receive as much scholarship money in their sports as the high revenue male teams?

Representation: Do women get the same amount of opportunities as men within sports leadership?

Do we have enough women working as A.D.'s?

Do you think positions within sports leadership are geared more towards men than women?

Team Sports: Who do you feel is represented in media coverage more, men or women? Why?

Do you feel Title IX is doing what it's supposed to do?

Do you feel like men would happily welcome a female player on their maledominated team?

\section{Appendix II}

\section{Interview}

Leadership: Do you think the presentation of women is sufficiently represented in sports leadership?

Do you think we need to increase female involvement in the leadership of collegiate team sports? How?

Do you think women are presented positively within sports leadership?

Coaching: Do you think men are more successful coaches?

Do you feel that women can coach all-male teams? Vice versa?

Do you think teams with female coaches are looked at like they are weaker than those coached my men?

Equal Pay: Do you think that women are paid as much as men in regards to professional pay?

Do you think that women receive more money in collegiate scholarship than men? Why

Do you think women should receive as much scholarship money in their sports as the high revenue male teams?

Representation: Do women get the same amount of opportunities as men within sports leadership?

Do we have enough women working as A.D.'s?

Do you think positions within sports leadership are geared more towards men than women?

Team Sports: Do you feel that women's teams are represented in media coverage to the extent of male teams? Why? 
Do you feel Title IX is doing what it's supposed to for women's collegiate teams? Do you feel like men would happily welcome a female player on their male-dominated team?

\section{References:}

1. Frey, James H., and Stanley D. Eitzen. "Sports and Society." Annual Review of Sociology 17 (August 1991): 503-22. doi:10.1146/annurev.so.17.080191.002443 Coakley, J.J. 1990. Sport in Society: Issues and Controversies, 4th ed. St. Louis: Times Mirror/Mosby. 375 pp.

2. Brooks, R. L. (1990). Rethinking the American race problem. Berkeley: University of California Press.

3. Harris, K., H. Grappendorf, C. Veraldo, and T. Aicher. 2014. "A Concern for the Future of Sports Management: Female Student's Perceptions towards Their Sport Management Degree." Global Sport Business Journal 2(3): 28-43.

4. International Platform on Sport and Development. 2013. "The Role of Sport in Addressing Gender Issues.” Accessed October 6, 2015. www.sportanddev.org/en/learnmore/ sport_and_gender/the_role_of_sport_in_addressing_gender_issues.

5. Kastelman, M. 2015. "The Difference between the Male and Female Brain." Net Nanny. Accessed October 6. www.netnanny.com/learn_center/article/165.

6. Kies, Ashley L. 2014. "Division I Collegiate Women Athletic Directors' Perceptions of Sexism and Career Experiences." PhDiss. University of Wisconsin Milwaukee.

7. Leberman, S. 2012. "Preparing Women to Compete in Sports Management." Accessed October 6. www.massey.ac.nz/massey/aboutmassey/news/article.cfm?mnarticle_ uuid= E96B1150-A1DD-D3F7-C1BD-2A48EB70A0E8.

8. Littlefield, B. 2015. "In Div. I, Small Gains for Female Athletic Directors.” WBUR Only a Game. April 25. Accessed September 23. http://onlyagame.wbur.org/2015/04/25/female-athletic-directorscollege-titleix.

9. Lopiano, D. 2008. Sports Management Resources. Accessed October 6, 2015. www.sportsmanagementresources.com/library/mediacoverage-womens-sports.

10. Rodak, Mike. 2016. "Kathryn Smith Hired by Bills as NFL's First Female Full-time Coach." ESPN. Accessed January 22. http://espn.go.com/nfl/story/_/id/14614558/kathryn-smith-hiredbuffalo-bills-nfl-first-full-female-assistant. 
11. Sabo, D.F. (1988). Title IX and athletics: Sex equity in schools. Updating School Board Policies, 19 (10), 14.

12. Sartore, Melanie L., and George B. Cunnigham. "Explaining the Under-Representation of Women in Leadership Positions of Sport Organizations: A Symbolic Interactionist Perspective." Quest 59, no. 2: 244-65. ?http://dx.doi.org/10.1080/00336297.2007.10483551.

13. Simmons, Katie. 2011. "Women in Top Management Positions in the Sport Industry: Breaking Down the Barriers and Stereotypes." St. John Fisher College. Accessed October 6. http://fisherpub.sjfc.edu/cgi/viewcontent.cgi?article=1031\&context=s port_undergrad.

14. Smith, P. 2015. "Women and Sport: Insight into the Growing Rise and Importance of Female Fans and Female Athletes." http://repucom.net/wp-content/uploads/2014/09/Women-and-SportRepucom.pdf.

15. Sportanddev.org Platform. 2016. "What is Gender'?" Accessed December 16, 2016. www.sportanddev.org/en/learnmore/gender/what-gender- 0 .

16. Title IX of the education amendments of 1972. 1990. 20 USC 16811688.

17. United Nations (UN). 2007. "Women, Gender Equality, and Sport." Accessed October 6, 2015. www.un.org/womenwatch/daw/public/Women\%20and\%20Sport.pdf.

18. Winslow, B. 2009. "The Impact of Title IX." Accessed September 23, 2015. www.gilderlehrman.org/history-byera/seventies/essays/impact-title-ix.

19. Women's Sports Foundation. 2015. "Pay Inequity in Athletics." June 20. Accessed October 2015. www.womenssportsfoundation.org/home/research/articles-andreports/equity-issues/pay-inequity.

20. Woods, R. B. 2015. Social Issues in Sport. 3rd ed. Champaign, IL: Human Kinetics. 